\title{
Prevention of diabetes in hypertensive patients: Results and implications from the VALUE trial
}

\author{
This article was published in the following Dove Press journal: \\ Vascular Health and Risk Management \\ 2I April 2009 \\ Number of times this article has been viewed
}

\author{
Ming-Sheng Zhou \\ Ivonne Hernandez Schulman \\ Nephrology-Hypertension Section, \\ Veterans Affairs Medical Center \\ and Division of Nephrology and \\ Hypertension and Vascular Biology \\ Institute, University of Miami Miller \\ School of Medicine, Miami, FL, USA
}

\begin{abstract}
A growing number of experimental and clinical studies have provided evidence indicating that pharmacological blockade of the renin-angiotensin system (RAS) by either angiotensin-converting enzyme inhibitors or angiotensin type 1 receptor blockers reduces the incidence of new onset type 2 diabetes in subjects with hypertension and/or cardiovascular disease, independently of antihypertensive and cardiovascular protective effects. The beneficial effects of RAS inhibition on the development of diabetes have been largely attributed to improvements in peripheral insulin sensitivity and glucose metabolism. This review focuses on recent experimental and clinical evidence supporting the role of RAS inhibition in the reduction of new onset type 2 diabetes and the mechanisms that may be involved.
\end{abstract}

Keywords: renin-angiotensin system, antihypertensive, diabetes

\section{Introduction}

According to the World Health Organization (WHO), more than 19 million adults in the US and 150 million adults worldwide have type 2 diabetes. ${ }^{1}$ It is projected that there will be more than 300 million cases worldwide by the year $2025 .^{1}$ Diabetics have a two-fold higher risk of cardiovascular morbidity than nondiabetic individuals. ${ }^{2}$ In addition, the prevalence of hypertension, an established risk factor for the development and progression of cardiovascular disease, is increasing in the US. ${ }^{3,4}$ It is estimated that hypertension affects $20 \%$ of the adult population and over 20 million adults in the US are receiving antihypertensive treatment. ${ }^{5}$

Of note, hypertension has been associated with an increased risk for the development of type 2 diabetes. About $50 \%$ of hypertensive individuals have hyperinsulinemia or glucose intolerance, whereas up to $80 \%$ of type 2 diabetic patients have hypertension. ${ }^{6}$ The association of hypertension with diabetes entails a greater increase in the risk of cardiovascular disease. Moreover, most patients with type 2 diabetes have insulin resistance, a condition that may precede the diagnosis of diabetes by up to 20 years. ${ }^{7}$ Clinical studies have shown that insulin resistance and hypertension are often associated and are central features of the metabolic syndrome, a significant risk factor for cardiovascular morbidity and mortality that affects over 40 million adults in the United States. $^{8}$

Antihypertensive agents may exert negative, neutral, or positive metabolic effects. ${ }^{9,10}$ Accumulating evidence suggests that the use of agents that impair glucose tolerance constitutes a risk factor for the development of type 2 diabetes. ${ }^{10,11}$ Thus, the treatment of hypertension in diabetic patients and prevention of new onset
Correspondence: Ming-Sheng Zhou of Miami Miller School of Medicine, Nephrology-Hypertension Section, Veterans Affairs Medical Center, I 201 NW I 6 Street, Room A- I009, Miami, FL 33125, USA

Tel +I 3055753103

$\mathrm{Fax}+\mathrm{I} 3055753378$

Email mzhou2@med.miami.edu 
type 2 diabetes (NOD) in patients receiving antihypertensive treatment constitute major health care challenges. There is now general agreement that therapeutic strategies should be assessed on the basis of prospective clinical trials prestratified for diabetes.

An increasing number of clinical studies, ${ }^{12-15}$ including the Valsartan Antihypertensive Long-term Use Evaluation (VALUE) trial, ${ }^{16,17}$ have provided evidence indicating that pharmacological blockade of the renin-angiotensin system (RAS) reduces the incidence of NOD in high-risk patients with cardiovascular disease. The beneficial effects of RAS inhibition on the development of diabetes have been largely attributed to improvements in peripheral insulin sensitivity and glucose metabolism. ${ }^{18,19}$ This review focuses on recent clinical and experimental evidence supporting the role of RAS inhibition in the reduction of NOD and the mechanisms that may be involved.

\section{Prevention of diabetes by RAS inhibition: Evidence from clinical studies}

Multiple large prospective trials have reported an unexpected reduction in the development of NOD in patients treated

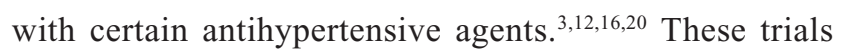
predominantly used angiotensin-converting enzyme (ACE) inhibitors and angiotensin receptor blockers (ARBs) and reported a reduction in the risk of NOD ranging from $15 \%$ to $35 \% .^{12,13,16,21}$

The VALUE ${ }^{16,17,22}$ trial was designed to compare cardiac outcomes in treatment regimens based on the ARB valsartan and the calcium channel blocker (CCB) amlodipine in a population of essential hypertensive patients recruited according to a specific predefined age- and risk factor-dependent algorithm. A total of 15,245 high-risk patients were followed for an average of 4.2 years. The results showed that there was no difference between the two drug regimens in the primary composite cardiac endpoint rate or in all-cause mortality. ${ }^{16}$ However, the relative risk of NOD, a pre-specified secondary end point, was $23 \%$ lower in the group receiving valsartan than in the amlodipine group. ${ }^{16,17,22}$ New diabetes was reported in $580(11.5 \%)$ patients in the valsartan group and in $718(14.5 \%)$ patients in the amlodipine group. In absolute terms, valsartan reduced NOD by $3 \%$ compared with amlodipine. ${ }^{17}$ This finding confirms and extends the results of the Antihypertensive and Lipid-Lowering Treatment to Prevent Heart Attack Trial (ALLHAT). ${ }^{23}$ In the ALLHAT study, the incidence of NOD in patients treated with the ACE inhibitor lisinopril was reduced by $30 \%$ compared with the thiazide diuretic chlorthalidone and by $17 \%$ compared with the CCB amlodipine. Based on the available experimental and clinical evidence, it has been proposed that RAS inhibitors exert a positive metabolic effect in terms of improvement in glucose intolerance and insulin resistance, ${ }^{9}$ CCBs exert a neutral metabolic effect, whereas diuretics and $\beta$-blockers exert negative metabolic effects. ${ }^{24,25}$ The ALLHAT and VALUE trials compared RAS inhibitors with the metabolically neutral amlodipine. ${ }^{12,16}$ The results of both trials support the notion that reduction in the incidence of NOD by RAS inhibitors is likely due to a direct beneficial effect of RAS blockade rather than a detrimental effect of the comparator drug.

The findings from the VALUE trial showing that RAS inhibition prevents the development of diabetes has been supported by a number of clinical studies. ${ }^{20,26,27}$ A recent meta-analysis of 13 randomized trials was done to determine if ACE inhibitors and/or ARBs prevent the development of type 2 diabetes. ${ }^{3}$ These trials enrolled 92,408 patients without diabetes, of whom 41,950 were randomized to treatment with an ACE inhibitor or ARB, while the remainder received active control ( $\mathrm{CCBs}$, thiazide diuretics, or $\beta$-blockers) or placebo. Nine of these trials randomized hypertensive patients. In this group, RAS inhibition resulted in a $27 \%$ reduction in the relative risk of NOD. NOD developed in $7.1 \%$ of patients on $\mathrm{ACE}$ inhibitors or ARBs versus 9.0\% of patients on placebo or other antihypertensive agent. Four of the trials randomized patients with vascular disease or left ventricular dysfunction. RAS inhibition reduced the incidence of NOD by $33 \%$. Diabetes developed in $6.7 \%$ of patients treated with an $\mathrm{ACE}$ inhibitor or $\mathrm{ARB}$, compared with $8.5 \%$ of patients on placebo or other agents. ACE inhibitors and ARBs had comparable effects on the development of diabetes. These clinical trials provide evidence that RAS inhibition with either ACE inhibitors or ARBs contributes to the prevention of diabetes.

According to the results from the Anglo-Scandinavian Cardiac Outcomes Trial - Blood Pressure Lowering Arm (ASCOT-BPLA), hypertensive individuals who have elevated fasting plasma glucose, triglycerides, or body mass index at baseline are at risk for the development of type 2 diabetes. ${ }^{28}$ These patients may benefit from the use of antihypertensive agents endowed with positive metabolic effects, such as ACE inhibitors or ARBs, or with metabolically neutral agents, such as CCBs, for the treatment of hypertension.

Of note, although substantial clinical evidence supports the notion that inhibition of RAS reduces the incidence of NOD in patients with hypertension or cardiovascular 
disease, the results from the Diabetes REduction Assessment with ramipril and rosiglitazone Medication (DREAM) trial showed that in patients with impaired glucose tolerance the ACE inhibitor ramipril did not significantly reduce the incidence of NOD (18.1\%) after three years of follow-up compared with placebo (19.5\%). ${ }^{29,30}$ Because patients with cardiovascular disease or uncontrolled hypertension were excluded from the DREAM trial, one possible explanation for the discrepancy between the DREAM trial and other clinical trials is the difference between the patient populations studied. However, participants receiving ramipril were more likely to have regression to normoglycemia than those receiving placebo (hazard ratio [HR] 1.16; 95\% confidence interval [CI], 1.07 to $1.27 ; \mathrm{p}=0.001$ ). In addition, at the end of the study, plasma glucose levels two hours after an oral glucose load were significantly lower in the ramipril group (135.1 mg per deciliter [7.50 mmol per liter] vs $140.5 \mathrm{mg}$ per deciliter [7.80 mmol per liter]; $\mathrm{p}=0.01$ ).

Most clinical trials, including the ALLHAT and VALUE trials, failed to detect a greater reduction in cardiovascular endpoints in patients treated with ACE inhibitors or ARBs compared with other agents. ${ }^{12,13,16,31}$ This raised the question of whether prevention of NOD by ACE inhibitors or ARBs translates into improvement in cardiovascular morbidity and mortality. Using previous data on the number of subjects needed to treat and to prevent one case of NOD and the estimated incidence of cardiovascular events, Verdecchia and colleagues calculated how many cardiovascular events specifically associated with NOD may be prevented by "new" (RAS inhibitors and CCBs) versus "old" (diuretics and $\beta$-blockers) antihypertensive agents. ${ }^{32}$ They reported that one NOD-associated cardiovascular event might be prevented for every 385 to 449 subjects treated with new rather than old antihypertensive agents for approximately four years. Therefore, the attempt to draw solid implications on the prognostic value of NOD from these randomized trials may be limited by the inadequacy of sample size and not by the lack of adverse prognostic value of NOD itself. Indeed, a recent post-hoc analysis of the VALUE trial database ${ }^{2}$ showed that patients with diabetes at baseline had higher cardiovascular morbidity (HR 2.2) than patients without diabetes. Patients who developed diabetes during antihypertensive treatment had a cardiovascular morbidity that was intermediate (HR 1.43) between diabetic and nondiabetic subjects. These results indicate that NOD predicts an excess risk of cardiovascular events $\mathrm{s}^{33}$ and it is important to identify patients at risk of developing diabetes in order to optimize lifestyle and medical interventions.

\section{Mechanisms underlying the reduction in incidence of NOD by RAS blockade}

The mechanisms underlying the prevention of NOD by RAS blockade are complex and not fully elucidated. Mechanisms that have been proposed include stimulation of intracellular insulin signaling in insulin-sensitive and vascular tissues, ${ }^{34,35}$ improvement of microvascular endothelial function leading to increased blood flow and glucose delivery and disposal in skeletal muscle, ${ }^{36,37}$ improvement of pancreatic $\beta$-cell function resulting in enhanced insulin secretion in response to glucose stimulation, ${ }^{38}$ and modulation of adipose tissue hormonal responses ${ }^{39,40}$ (Figure 1).

\section{Stimulation of insulin signaling} in insulin-sensitive tissues and vascular cells Insulin and angiotensin II are two important hormones in the control of metabolic and hemodynamic homeostasis, respectively. Recent studies have suggested that the signal transduction pathways of insulin and angiotensin II share a number of downstream effectors and cross-talk at multiple levels. ${ }^{41}$ In pathophysiologic conditions such as hypertension and diabetes, activation of RAS inhibits insulin signaling in insulin sensitive tissues as well as vascular cells,${ }^{42}$ resulting in development of insulin resistance and progression of cardiovascular disease. Inhibition of RAS by either ACE inhibitors or ARBs has been shown to improve insulin signaling and insulin sensitivity in clinical ${ }^{43}$ and experimental studies. ${ }^{35}$

The insulin signaling pathway is initiated by circulating insulin binding to its receptor, after which the insulin receptor undergoes rapid tyrosine autophosphorylation that activates the receptor kinase and allows transient interaction with insulin receptor substrates (IRSs). Interaction of tyrosine phosphorylated IRS-1 with the p85 regulatory subunit of phosphatidylinositol 3-kinase (PI3K) results in activation of PI3K and phosphorylation of Akt. ${ }^{44}$ Phosphorylated Akt stimulates translocation of Glut-4 to the sarcolemma to facilitate glucose entry into the cell. Intracellular glucose is then rapidly phosphorylated by hexokinase and directed to oxidative or nonoxidative pathways. ${ }^{45}$

It has been shown that angiotensin II exerts an inhibitory effect on insulin stimulation of the PI3K pathway. ${ }^{41}$ In cultured L6 myocytes, angiotensin II stimulates serinephosphorylation of IRS- $1 .^{46}$ IRS- 1 is one of the major substrates of the insulin receptor kinase and contains multiple tyrosine phosphorylation motifs that serve as docking sites for $\mathrm{SH}_{2}$ domains that mediate the metabolic and 


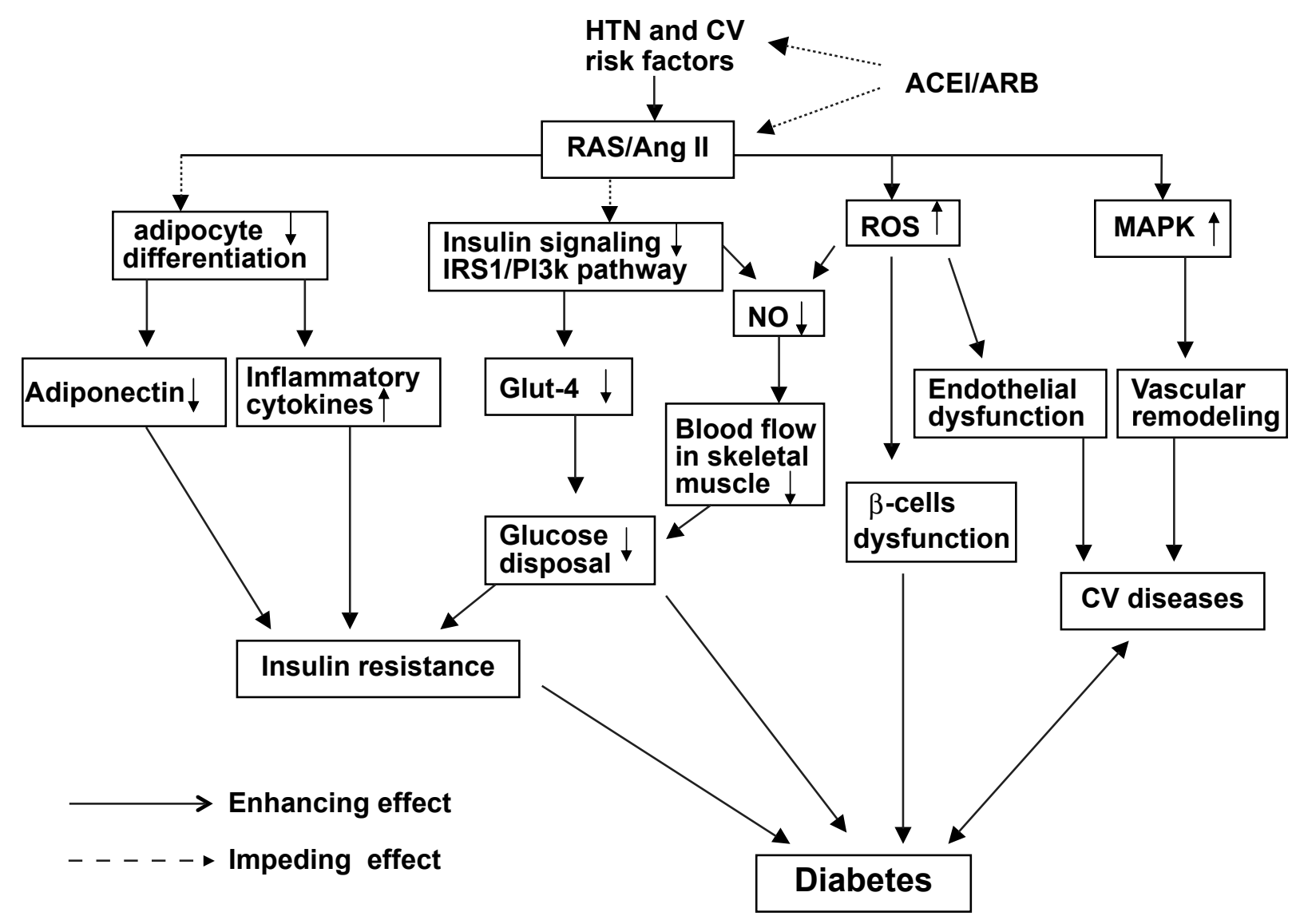

Figure I Schemata of mechanisms underlying the prevention of diabetes development by inhibition of the renin-angiotensin system (RAS). Hypertension (HTN) and cardiovascular (CV) risk factors are commonly associated with activation of the RAS. Activation of angiotensin II produces the following biological effects: I) inhibition of insulin activation of the phosphatidylinositol 3-kinase (PI3K) signaling pathway; 2) inhibition of pre-adipocyte differentiation into mature adipocytes, leading to reduction in secretion of adiponectin and increase in inflammatory cytokine production; 3 ) increased reactive oxygen species (ROS) production, resulting in islet structural damage and $\beta$-cell dysfunction; 4 ) activation of the mitogen-activated protein kinase (MAPK) pathway, leading to vascular remodeling and promotion of CV disease. All of these biological effects cause impairment of glucose metabolism and insulin resistance, thus contributing to the development of diabetes. Inhibition of RAS by either angiotensin converting enzyme inhibitors (ACEI) or angiotensin II type I receptor blockers (ARB) prevents these detrimental effects of angiotensin II on glucose metabolism and insulin resistance, therefore potentially reducing the development of diabetes and cardiovascular complications.

Abbreviation: IRSI, insulin receptor substrate-I.

growth-promoting functions of insulin. IRS-1 also contains over 30 potential serine/threonine phosphorylation sites. Phosphorylation of IRS-1 at serine/threonine inhibits insulin stimulation of tyrosine phosphorylation, resulting in inhibition of downstream insulin signaling molecules. ${ }^{47}$ It has been shown that phosphorylation of IRS-1 at Ser 612 (human Ser616) and Ser307 (human Ser312) inhibits the insulin/PI3K signaling pathway. ${ }^{47}$ The phosphorylation of IRS-1 at Ser612 causes dissociation of the p85 subunit of PI3K, inhibiting downstream signaling, whereas the phosphorylation of IRS-1 on Ser307 results in its dissociation from the insulin receptor and triggers proteasomedependent degradation. It has been shown that angiotensin II induces serine phosphorylation at both sites and inhibits downstream signaling, including Akt phosphorylation and Glut-4 translocation to the sarcolemma, therefore inhibiting glucose uptake. The underlying mechanisms may involve angiotensin II stimulation of reactive oxygen species (ROS) production. ${ }^{35,46,48}$

In the vasculature, insulin stimulates phosphorylation of endothelial nitric oxide synthase (NOS) at Ser1179 through activation of the PI3K pathway, resulting in nitric oxide (NO)-mediated vasorelaxation, which increases blood flow and glucose delivery to the skeletal muscle. ${ }^{37,49} \mathrm{NO}$ exerts important vasoprotective effects in the cardiovascular system. Thus, constitutive stimulation of NO production by insulin may play an important role in the maintenance of vascular health as well as regulation of glucose metabolism. ${ }^{49}$ It has been shown that in vascular endothelial cells, angiotensin II, by interfering with the PI3K signaling pathway, impairs insulin stimulation of NO production. ${ }^{49}$ In addition, insulin stimulates the mitogen-activated protein kinase (MAPK) 
pathway to promote cellular growth and migration. ${ }^{49}$ In insulin resistant states such as hypertension and diabetes, insulin-stimulation of the PI3K pathway is selectively impaired and overactivation of RAS and hyperinsulinemia may synergistically stimulate the MAPK pathway, which may contribute to the development of cardiovascular complications. Inhibition of angiotensin II, by either ACE inhibition or angiotensin receptor blockade, improves insulin activation of the PI3K pathway, thus facilitating Glut-4 translocation and glucose uptake in insulin-sensitive tissues and enhancing NO-mediated vasorelaxation. The increased capillary recruitment, blood flow, and glucose disposal in skeletal muscle improve systemic insulin sensitivity and potentially reduce cardiovascular complications.

\section{Improvement of glucose metabolism}

As described above, angiotensin II has an inhibitory effect on insulin-mediated PI3K activation, which is mainly mediated by activation of the angiotensin II type 1 (AT1) receptor. Experimental studies have shown that the chronic administration of ARBs significantly improve systemic glucose metabolism in various animal models of insulin resistance, including the obese Zucker rats, spontaneously hypertensive rats, and fructose-fed rats. ${ }^{50,51}$ The Dahl salt-sensitive (DS) rat is an animal model of salt-induced hypertension and cardiovascular disease. We have demonstrated that the hypertensive DS rat manifests metabolic insulin resistance, determined by hyperinsulinemic euglycemic clamp, impaired endothelium-dependent relaxation to acetylcholine and insulin, accompanied by increased vascular superoxide production. ${ }^{35,52}$ Treatment with the ARB candesartan or antioxidant tempol improved systemic insulin sensitivity and acetylcholine- and insulin-mediated vasorelaxation, suggesting that angiotensin II-mediated ROS overproduction interferes with insulin signaling pathways in both metabolic and cardiovascular tissues in this hypertensive animal model. ${ }^{35}$

The skeletal muscle is the largest insulin-sensitive tissue in the body and primary site for insulin-stimulated glucose metabolism. The skeletal muscle comprises $40 \%-50 \%$ of body mass and handles over $75 \%$ of insulin-mediated glucose disposal. ${ }^{45,53}$ Studies with rodent models suggest that angiotensin II may play an important role in the etiology of skeletal muscle insulin resistance. For example, systemic or local infusion of angiotensin II produced insulin resistance in skeletal muscle independent of hemodynamic effects. ${ }^{42,54}$ Studies in TG(mREN2)27 rats, ${ }^{53}$ which harbor the mouse Ren-2 renin gene and are a transgenic model with elevation of systemic and local (skeletal muscle) angiotensin II levels, ${ }^{55}$ have shown that they exhibit whole-body and skeletal muscle insulin resistance, associated with enhanced ROS production and defective activation of the IRS-1/PI3K/Akt pathway. ${ }^{53,56}$ Furthermore, tempol improved insulin sensitivity and insulin-mediated glucose uptake in the skeletal muscle, suggesting that angiotensin II impairs insulin action on skeletal muscle glucose metabolism at least in part through generation of ROS.

\section{Protection of pancreatic $\beta$-cell function}

It has been shown that the pancreas expresses all components of the RAS, which modulates a range of activities including local blood flow, hormone release, and prostaglandin synthesis. Activation of the local (islet) RAS may increase oxidative stress, inflammation, and free fatty acid levels, which potentially contributes to $\beta$-cell dysfunction in diabetes. ${ }^{57}$ Experimental studies have provided evidence that blockade of RAS improves islet structure and function by increased blood flow and oxygen tension and inhibition of oxidative injury. ${ }^{39,58,59}$ Tikellis and colleagues ${ }^{58}$ showed that blockade of RAS by either an ACE inhibitor (perindopril) or ARB (irbesartan) attenuated islet fibrosis, apoptosis, and oxidative stress in Zucker diabetic fatty rats, a type 2 diabetic animal model. In the $\mathrm{db} / \mathrm{db}$ mouse model, chronic AT1 receptor blockade decreased NADPH oxidase-induced oxidative stress and downregulated expression of mitochondrial uncoupling protein 2 (UCP2), which is associated with improved $\beta$-cell insulin secretion and reduced apoptosisinduced $\beta$-cell mass loss. ${ }^{60}$ Interestingly, recent studies also showed that hyperglycemia can activate the RAS in pancreatic islet and stellate cells. ${ }^{57}$ Therefore, RAS blockade may ameliorate the angiotensin II-induced pancreatic inflammation and fibrosis aggravated by chronic exposure to high glucose levels.

\section{Modulation of adipocytokines}

Obesity is a common cause of insulin resistance and one of the strongest risk factors for the development of type 2 diabetes. ${ }^{61}$ The increasing prevalence of obesity has largely contributed to the increasing incidence of type 2 diabetes and cardiovascular disorders. ${ }^{61}$ Adipose tissue does not only store energy, but is increasingly recognized as an active endocrine and paracrine organ that produces and releases a large number of cytokines and bioactive mediators that are collectively referred to as adipocytokines. ${ }^{62,63}$ Some adipocytokines, such as tumor necrosis factor- $\alpha$ $(\mathrm{TNF}-\alpha)$ and nuclear factor kappa B (NF $\kappa \mathrm{B})$, can inhibit 
insulin signaling and exert diabetogenic effects, whereas other adipocytokines, ${ }^{64,65}$ such as adiponectin, exert antidiabetic effects. Adiponectin appears to be secreted in higher levels by small (differentiated) adipocytes and found circulating in lower levels in patients with essential hypertension or type 2 diabetes. ${ }^{66}$ Large adipocytes produce diabetogenic adipocytokines, such as TNF- $\alpha$ and plasminogen activator inhibitor (PAI)-1, secrete less adiponectin, and cause insulin resistance. Considering that inhibition of angiotensin II reduces the incidence of type 2 diabetes and that adipocytes express all components of the RAS, including angiotensinogen, ACE, AT1, and AT2 receptors, it has been proposed that blockade of RAS may promote the recruitment and differentiation of pre-adipocytes and increased formation of small insulin-sensitive adipocytes, thereby improving insulin sensitivity. ${ }^{66}$ Indeed, several recent studies have provided evidence showing that angiotensin II inhibits adipogenic differentiation of human adipocytes via the AT1 receptor ${ }^{67}$ and inhibition of angiotensin II by ACE inhibitors or ARBs increases the number of small differentiated insulin sensitive adipocytes and decreases large adipocytes. ${ }^{38,40,67}$ In the OLEFT rat, a model of type 2 diabetes, Lee and colleagues $^{38}$ showed that treatment with an ARB improves the differentiation of adipocytes and inhibits activation of the inflammatory process in adipose tissue, accompanied by an increase in adiponectin and a decrease in NF $\kappa \mathrm{B}$, PAI-1, and monocyte chemoattractant protein-1. Therefore, the modulation of adipocytokine production by blockade of RAS may be another mechanism for the prevention of diabetes.

\section{Conclusion}

Accumulating experimental evidence indicates that activation of the RAS plays an important role in the development of insulin resistance, glucose intolerance, and type 2 diabetes. ${ }^{19,41}$ Although clinical studies are needed to confirm these experimental findings, a growing number of clinical trials support the notion that RAS blockade exerts antidiabetogenic effects in patients with hypertension and cardiovascular disease. ${ }^{18,68}$ Further research is necessary to identify patients at risk for development of diabetes and other cardiovascular complications and those who would most benefit from RAS blockade.

\section{Acknowledgments}

This work was supported by an American Heart Association Scientist Development Award and a University of Miami
SAC Research Grant to Ming-Sheng Zhou. The authors report no conflicts of interest in this work.

\section{References}

1. King H. Epidemiology of glucose intolerance and gestational diabetes in women of childbearing age. Diabetes Care. 1998;21 Suppl 2:B9-B13.

2. Aksnes TA, Kjeldsen SE, Rostrup M, Omvik P, Hua TA, Julius S. Impact of new-onset diabetes mellitus on cardiac outcomes in the Valsartan Antihypertensive Long-term Use Evaluation (VALUE) trial population. Hypertension. 2007;50:467-473.

3. Bangalore S, Parkar S, Grossman E, Messerli FH. A meta-analysis of 94,492 patients with hypertension treated with beta blockers to determine the risk of new-onset diabetes mellitus. Am J Cardiol. 2007; 100:1254-1262.

4. Alberti KG, Zimmet P, Shaw J. The metabolic syndrome - a new worldwide definition. Lancet. 2005;366:1059-1062.

5. Cutler JA, Sorlie PD, Wolz M, Thom T, Fields LE, Roccella EJ. Trends in hypertension prevalence, awareness, treatment, and control rates in United States adults between 1988-1994 and 1999-2004. Hypertension. 2008;52:818-827.

6. Bonora E, Targher G, Alberiche M, Bonadonna RC, Zenere MB, Saggiani F, Muggeo M. Intracellular partition of plasma glucose disposal in hypertensive and normotensive subjects with type 2 diabetes mellitus. J Clin Endocrinol Metab. 2001;86:2073-2079.

7. Paton RC. The natural history of type II diabetes. Practical Diabetes. 1989;6:10-13.

8. Sowers JR. Insulin resistance and hypertension. Am J Physiol Heart Circ Physiol. 2004;286:H1597-H602.

9. Mancia G, Grassi G, Zanchetti A. New-onset diabetes and antihypertensive drugs. J Hypertens. 2006;24:3-10.

10. Gress TW, Nieto FJ, Shahar E, Wofford MR, Brancati FL. Hypertension and antihypertensive therapy as risk factors for type 2 diabetes mellitus. Atherosclerosis Risk in Communities Study. N Engl J Med. 2000;342:905-912.

11. Mason JM, Dickinson HO, Nicolson DJ, Campbell F, Ford GA, Williams B. The diabetogenic potential of thiazide-type diuretic and beta-blocker combinations in patients with hypertension. J Hypertens. 2005;23:1777-1781.

12. Major outcomes in high-risk hypertensive patients randomized to angiotensin-converting enzyme inhibitor or calcium channel blocker vs diuretic: The Antihypertensive and Lipid-Lowering Treatment to Prevent Heart Attack Trial (ALLHAT). JAMA. 2002;288: 2981-2997.

13. Hansson L, Lindholm LH, Niskanen L, et al. Effect of angiotensinconverting-enzyme inhibition compared with conventional therapy on cardiovascular morbidity and mortality in hypertension: the Captopril Prevention Project (CAPPP) randomised trial. Lancet. 1999;353: 611-616.

14. Pfeffer MA, Swedberg K, Granger CB, et al. Effects of candesartan on mortality and morbidity in patients with chronic heart failure: the CHARM-Overall programme. Lancet. 2003;362:759-766.

15. Yusuf S, Sleight P, Pogue J, Bosch J, Davies R, Dagenais G. Effects of an angiotensin-converting-enzyme inhibitor, ramipril, on cardiovascular events in high-risk patients. The Heart Outcomes Prevention Evaluation Study Investigators. $N$ Engl J Med. 2000;342:145-153.

16. Julius S, Kjeldsen SE, Weber M, et al. Outcomes in hypertensive patients at high cardiovascular risk treated with regimens based on valsartan or amlodipine: the VALUE randomised trial. Lancet. 2004;363:2022-2031.

17. Julius S, Weber MA, Kjeldsen SE, et al. The Valsartan Antihypertensive Long-Term Use Evaluation (VALUE) trial: outcomes in patients receiving monotherapy. Hypertension. 2006;48:385-391.

18. McGuire DK, Winterfield JR, Rytlewski JA, Ferrannini E. Blocking the renin-angiotensin-aldosterone system to prevent diabetes mellitus. Diab Vasc Dis Res. 2008;5:59-66. 
19. Jandeleit-Dahm KA, Tikellis C, Reid CM, Johnston CI, Cooper ME. Why blockade of the renin-angiotensin system reduces the incidence of new-onset diabetes. J Hypertens. 2005;23:463-473.

20. Andraws R, Brown DL. Effect of inhibition of the renin-angiotensin system on development of type 2 diabetes mellitus (meta-analysis of randomized trials). Am J Cardiol. 2007;99:1006-1012.

21. Wing LM, Reid CM, Ryan P, et al. A comparison of outcomes with angiotensin-converting-enzyme inhibitors and diuretics for hypertension in the elderly. N Engl J Med. 2003;348:583-592.

22. Kjeldsen SE, Julius S, Mancia G, et al. Effects of valsartan compared to amlodipine on preventing type 2 diabetes in high-risk hypertensive patients: the VALUE trial. J Hypertens. 2006;24:1405-1412.

23. Barzilay JI, Davis BR, Cutler JA, et al. Fasting glucose levels and incident diabetes mellitus in older nondiabetic adults randomized to receive 3 different classes of antihypertensive treatment: a report from the Antihypertensive and Lipid-Lowering Treatment to Prevent Heart Attack Trial (ALLHAT). Arch Intern Med. 2006;166:2191-2201.

24. Macfarlane DP, Paterson KR, Fisher M. Cardiovascular drugs as antidiabetic agents: evidence for the prevention of type 2 diabetes. Diabetes Obes Metab. 2008;10:533-544.

25. Eriksson JW, Jansson PA, Carlberg B, et al. Hydrochlorothiazide, but not candesartan, aggravates insulin resistance and causes visceral and hepatic fat accumulation: the mechanisms for the diabetes preventing effect of Candesartan (MEDICA) Study. Hypertension. 2008;52:1030-1037.

26. Abuissa H, Jones PG, Marso SP, O’Keefe JH Jr. Angiotensin-converting enzyme inhibitors or angiotensin receptor blockers for prevention of type 2 diabetes: a meta-analysis of randomized clinical trials. J Am Coll Cardiol. 2005;46:821-826.

27. Scheen AJ. Renin-angiotensin system inhibition prevents type 2 diabetes mellitus. Part 1. A meta-analysis of randomised clinical trials. Diabetes Metab. 2004;30:487-496.

28. Dahlof B, Sever PS, Poulter NR, et al. Prevention of cardiovascular events with an antihypertensive regimen of amlodipine adding perindopril as required versus atenolol adding bendroflumethiazide as required, in the Anglo-Scandinavian Cardiac Outcomes Trial-Blood Pressure Lowering Arm (ASCOT-BPLA): a multicentre randomised controlled trial. Lancet. 2005;366:895-906.

29. Bosch J, Yusuf S, Gerstein HC, et al. Effect of ramipril on the incidence of diabetes. N Engl J Med. 2006;355:1551-1562.

30. Gerstein HC, Yusuf S, Bosch J, et al. Effect of rosiglitazone on the frequency of diabetes in patients with impaired glucose tolerance or impaired fasting glucose: a randomised controlled trial. Lancet. 2006; 368:1096-1105.

31. Weber MA, Julius S, Kjeldsen SE, et al. Blood pressure dependent and independent effects of antihypertensive treatment on clinical events in the VALUE Trial. Lancet. 2004;363:2049-2051.

32. Verdecchia P, Angeli F, Reboldi G. New-onset diabetes, antihypertensive treatment, and outcome. Hypertension. 2007;50:459-460.

33. Verdecchia P, Reboldi G, Angeli F, et al. Adverse prognostic significance of new diabetes in treated hypertensive subjects. Hypertension. 2004;43:963-969.

34. Shiuchi T, Iwai M, Li HS, et al. Angiotensin II type-1 receptor blocker valsartan enhances insulin sensitivity in skeletal muscles of diabetic mice. Hypertension. 2004;43:1003-1010.

35. Zhou MS, Schulman IH, Raij L. The role of angiotensin II and oxidative stress in vascular insulin resistance linked to hypertension. Am J Physiol Heart Circ Physiol. 2009;296:H833-H839.

36. Kim JA, Montagnani M, Koh KK, Quon MJ. Reciprocal relationships between insulin resistance and endothelial dysfunction: molecular and pathophysiological mechanisms. Circulation. 2006;113:1888-1904.

37. Steinberg HO, Brechtel G, Johnson A, Fineberg N, Baron AD. Insulin-mediated skeletal muscle vasodilation is nitric oxide dependent. A novel action of insulin to increase nitric oxide release. J Clin Invest. 1994;94:1172-1179.

38. Lee MH, Song HK, Ko GJ, et al. Angiotensin receptor blockers improve insulin resistance in type 2 diabetic rats by modulating adipose tissue. Kidney Int. 2008;74:890-900.
39. Tikellis C, Cooper ME, Thomas MC. Role of the renin-angiotensin system in the endocrine pancreas: implications for the development of diabetes. Int J Biochem Cell Biol. 2006;38:737-751.

40. Sharma AM, Janke J, Gorzelniak K, Engeli S, Luft FC. Angiotensin blockade prevents type 2 diabetes by formation of fat cells. Hypertension . 2002;40:609-611.

41. Folli F, Kahn CR, Hansen H, Bouchie JL, Feener EP. Angiotensin II inhibits insulin signaling in aortic smooth muscle cells at multiple levels - A potential role for serine phosphorylation in insulin/angiotensin II crosstalk. J Clin Invest. 1997;100:2158-2169.

42. Wei Y, Sowers JR, Clark SE, Li W, Ferrario CM, Stump CS. Angiotensin II-induced skeletal muscle insulin resistance mediated by NF-kappaB activation via NADPH oxidase. Am J Physiol Endocrinol Metab. 2008;294:E345-E351.

43. Gillespie EL, White CM, Kardas M, Lindberg M, Coleman CI. The impact of ACE inhibitors or angiotensin II type 1 receptor blockers on the development of new-onset type 2 diabetes. Diabetes Care. 2005;28:2261-2266.

44. Esposito DL, Li YH, Cama A, Quon MJ. Tyr(612) and Tyr(632) in human insulin receptor substrate-1 are important for full activation of insulinstimulated phosphatidylinositol 3-kinase activity and translocation of GLUT4 in adipose cells. Endocrinology. 2001;142:2833-2840.

45. Stump CS, Henriksen EJ, Wei Y, Sowers JR. The metabolic syndrome: role of skeletal muscle metabolism. Ann Med. 2006;38:389-402.

46. Wei Y, Sowers JR, Nistala R, et al. Angiotensin II-induced NADPH oxidase activation impairs insulin signaling in skeletal muscle cells. J Biol Chem. 2006;281:35137-35146.

47. Andreozzi F, Laratta E, Sciacqua A, Perticone F, Sesti G. Angiotensin II impairs the insulin signaling pathway promoting production of nitric oxide by inducing phosphorylation of insulin receptor substrate-1 on Ser(312) and Ser(616) in human umbilical vein endothelial cells. Circ Res. 2004;94:1211-1218.

48. Taniyama Y, Hitomi H, Shah A, Alexander RW, Griendling KK. Mechanisms of reactive oxygen species-dependent downregulation of insulin receptor substrate-1 by angiotensin II. Arteriosclers Thromb Vasc Biol. 2005;25:1142-1147.

49. Schulman IH, Zhou MS. Vascular insulin resistance: A potential link between cardiovascular and metabolic diseases. Curr Hypertens Rep. 2009; 11:48-55.

50. Henriksen EJ, Jacob S, Kinnick TR, Teachey MK, Krekler M. Selective angiotensin II receptor antagonism reduces insulin resistance in obese Zucker rats. Hypertension. 2001;38:884-890.

51. Henriksen EJ. Improvement of insulin sensitivity by antagonism of the renin-angiotensin system. Am J Physiol Regul Integr Comp Physiol. 2007;293:R974-R980.

52. Zhou MS, Hernandez Schulman I, Pagano PJ, Jaimes EA, Raij L. Reduced $\mathrm{NAD}(\mathrm{P}) \mathrm{H}$ oxidase in low renin hypertension: link among angiotensin II, atherogenesis, and blood pressure. Hypertension. 2006;47:81-86.

53. Sloniger JA, Saengsirisuwan V, Diehl CJ, et al. Defective insulin signaling in skeletal muscle of the hypertensive TG(mREN2)27 rat. Am J Physiol Endocrinol Metabol. 2005;288:E1074-E1081.

54. Wei Y, Chen K, Whaley-Connell AT, Stump CS, Ibdah JA, Sowers JR. Skeletal muscle insulin resistance: role of inflammatory cytokines and reactive oxygen species. Am J Physiol Regul Integr Comp Physiol. 2008; 294:R673-R680.

55. Lee MA, Bohm M, Paul M, Bader M, Ganten U, Ganten D. Physiological characterization of the hypertensive transgenic rat TGR(mREN2)27. Am J Physiol. 1996;270:E919-E929.

56. Blendea MC, Jacobs D, Stump CS, et al. Abrogation of oxidative stress improves insulin sensitivity in the Ren-2 rat model of tissue angiotensin II overexpression. Am J Physiol Endocrinol Metabol. 2005;288: E353-E359.

57. Leung PS. The physiology of a local renin-angiotensin system in the pancreas. J Physiol. 2007;580:31-37.

58. Tikellis C, Wookey PJ, Candido R, Andrikopoulos S, Thomas MC, Cooper ME. Improved islet morphology after blockade of the reninangiotensin system in the ZDF rat. Diabetes. 2004;53:989-997. 
59. Ko SH, Kwon HS, Kim SR, et al. Ramipril treatment suppresses islet fibrosis in Otsuka Long-Evans Tokushima fatty rats. Biochem Biophys Res Commun. 2004;316:114-122.

60. Diao J, Allister EM, Koshkin V, et al. UCP2 is highly expressed in pancreatic alpha-cells and influences secretion and survival. Proc Natl Acad Sci U S A. 2008;105:12057-12062.

61. Van Gaal LF, Mertens IL, De Block CE. Mechanisms linking obesity with cardiovascular disease. Nature. 2006;444:875-880.

62. Engeli S, Negrel R, Sharma AM. Physiology and pathophysiology of the adipose tissue renin-angiotensin system. Hypertension. 2000;35: 1270-1277.

63. Lumeng CN, Bodzin JL, Saltiel AR. Obesity induces a phenotypic switch in adipose tissue macrophage polarization. J Clin Invest. 2007;117: 175-184.

64. de Alvaro C, Teruel T, Hernandez R, Lorenzo M. Tumor necrosis factor alpha produces insulin resistance in skeletal muscle by activation of inhibitor kappaB kinase in a p38 MAPK-dependent manner. $J$ Biol Chem. 2004;279:17070-17078.
65. Cai D, Yuan M, Frantz DF, et al. Local and systemic insulin resistance resulting from hepatic activation of IKK-beta and NF-kappaB. Nat Med. 2005;11:183-190.

66. Furuhashi M, Ura N, Higashiura K, et al. Blockade of the renin-angiotensin system increases adiponectin concentrations in patients with essential hypertension. Hypertension. 2003;42:76-81.

67. Furuhashi M, Ura N, Takizawa $H$, et al. Blockade of the renin-angiotensin system decreases adipocyte size with improvement in insulin sensitivity. J Hypertens. 2004;22:1977-1982.

68. Aksnes TA, Kjeldsen SE, Mancia G. The effect of antihypertensive agents on new-onset diabetes mellitus: time to amend the guidelines? Am J Cardiovasc Drugs. 2006;6:139-147.

\section{Publish your work in this journal}

Vascular Health and Risk Management is an international, peerreviewed journal of therapeutics and risk management, focusing on concise rapid reporting of clinical studies on the processes involved in the maintenance of vascular health; the monitoring, prevention and treatment of vascular disease and its sequelae; and the involvement of metabolic disorders, particularly diabetes. This journal is indexed on PubMed Central and MedLine. The manuscript management system is completely online and includes a very quick and fair peer-review system, which is all easy to use. Visit http://www.dovepress.com/ testimonials.php to read real quotes from published authors. 